\title{
Cuerpos bioconstruidos: espacios de participación ciudadana para imaginar y domesticar las corporalidades del mañana*
}

\author{
Bioconstructed bodies: a citizen engagement exercise to imagine \\ and domesticate the bodies of tomorrow
}

\author{
Corpos bioconstruídos: espaços de participação cidadã para \\ imaginar e domesticar as corporalidades do futuro
}

\footnotetext{
* Antropóloga y MSc en Bioética de la Pontificia Universidad Javeriana de Bogotá. Profesora del departamento de derecho y ciencias sociales de la Universidad Icesi. Ha sido profesora invitada en la maestría de administración en salud de la escuela de salud pública de la Universidad del Valle. Correo electrónico: raquel.diaz@correo.icesi.edu.co. Número de identificación ORCID: 0ooo-0oo2-3023-9974

${ }^{* *}$ El presente artículo se desprende del trabajo de grado para optar al título de Maestría en Bioética de la Pontificia Universidad Javeriana de Bogotá. Dicho proyecto lleva por título «Cuerpos bioconstruidos: las expectativas de los jóvenes colombianos frente a las nuevas corporalidades que introduce la biotecnología médica», y fue realizado bajo la tutoría del profesor Eduardo Rueda Barrera entre enero de 2014 y mayo de 2015. Se agradece a la compañía Caladrius Biosciences por haber financiado mi participación en el «Second International Vatican Adult Stem Cell Conference, Regenerative Medicine: A fundamental Shift in Science and Culture», realizada en la ciudad del Vaticano entre el 10 y el 13 de abril de 2013. Gracias al profesor Eduardo por la motivación para investigar estos temas y a Karime Ríos por las transcripciones y el sondeo. A mis padres, mi hermano y a Diego Cagüeñas, gracias por toda la ayuda en la logística de estas actividades y sus observaciones. Finalmente, mi agradecimiento va hacia todos jóvenes que imaginaron un futuro para estos cuerpos bioconstruidos. Artículo recibido el 15-01-2018 y aprobado 03-10-2018.
} 


\section{Cómo citar}

Díaz Bustamante, R. (2018). Cuerpos bioconstruidos: espacios de participación ciudadana para imaginar y domesticar las corporalidades del futuro. Revista CS, (26), 45-73.

DOI: https://doi.org/10.18046/recs.i26.2699 
Resumen

Abstract

Resumo

El presente artículo analiza las representaciones del futuro que un grupo de jóvenes universitarios construyen a propósito de dos casos de modificación corporal por el uso de tecnologías médicas y robóticas. Para esto, se diseñó un espacio de participación ciudadana en donde se aplicaron dos técnicas cualitativas prospectivas que permitieron a los participantes compartir sus expectativas y reflexionar sobre dilemas bioéticos que pueden emerger por el uso de estas tecnologías en un país como Colombia, para el año 2034. Este trabajo busca construir puentes entre la bioética, la antropología y los estudios sociales de la ciencia y la tecnología, con el objetivo de reflexionar sobre el impacto de la implementación de estas tecnologías en la configuración de los valores morales y categorías culturales con las que los colombianos interpretarán la naturaleza de los cuerpos humanos en el futuro.

\section{PALABRAS CLAVE:}

Bioética; Espacios de participación ciudadana; Metodologías prospectivas; Antropología del cuerpo; Cíborgs; Transhumanismo; Mercantilización del cuerpo; Tráfico de órganos y tejidos

The following article analyses how a group of undergraduate students imagines the future based on two case studies that focus on the transformation of the human body using biomedical technologies and robotic prosthetics. Prospective qualitative methods were used to design a citizen engagement exercise that encouraged participants to share their expectations and reflect on the ethical problems that could emerge, when these bodies become a reality in Colombia in the year 2034. This paper aims to build bridges between the fields of bioethics, anthropology and the social studies of science and technology, to reflect on the potential impact that the use of medical technology and robotic artifacts would have on the moral values and cultural categories that Colombians will use to interpret the nature of the human body in the future.

\section{KEYWORDS:}

Bioethics; Citizen Engagement Exercise; Prospective methods; Anthropology of the body; Cyborgs; Transhumanism; Commodification of the body; Organ Trafficking 
Este artigo analisa as representações do futuro que um grupo de jovens universitários constroem em relação a dois casos de modificação corporal por meio do uso de tecnologias médicas e robóticas. Para isso, foi elaborado um espaço para participação cidadã, onde foram aplicadas duas técnicas qualitativas prospectivas que permitiram aos participantes compartilhar suas expectativas e refletir sobre os dilemas bioéticos que podem surgir em decorrência do uso dessas tecnologias em um país como a Colômbia, para o ano 2034. Este trabalho procura construir pontes entre a bioética, a antropologia $\mathrm{e}$ estudos sociais de ciência e tecnologia com o objetivo de refletir sobre o impacto da implementação dessas tecnologias na configuração de valores morais e categorias culturais com as quais os colombianos interpretarão a natureza dos corpos humanos no futuro.

\section{PALAVRAS CHAVE:}

Bioética; Espaços de participação cidadã; Metodologias prospectivas; Antropologia do corpo; Ciborgues; Transhumanismo; Mercantilização do corpo; Tráfico de órgãos e tecido 


\section{Introducción}

A sus 33 años, Neil Harbisson elige qué vestir a partir de la armonía que producen las notas que componen el color de una prenda. Él no es un ser humano cualquiera; percibe el mundo en blanco y negro, producto de una enfermedad congénita llamada acromatopsia, que altera las células fotorreceptoras de sus ojos; pero gracias a un eyeborg puede llevar una vida autónoma, moviéndose por el mundo escuchando el color y sus sonidos. Dicho dispositivo se encuentra adaptado a su cabeza y cada vez que capta un color produce vibraciones que viajan por los huesos de su cráneo para ser traducidas en ondas sonoras.

Harbisson es considerado uno de los primeros ciudadanos cíborgs del Reino Unido, según lo reconoce su pasaporte. Él es uno de los primeros seres humanos cuyos cuerpos y subjetividades han sido transformados por el uso continuo de artefactos. Además, su nuevo cuerpo despierta todo tipo de imaginarios y temores debido a su novedad y a su naturaleza no del todo humana. Pensar a este individuo como sujeto cíborg nos lleva a imaginar y concebir nuevas formas de definir lo que es una persona, a partir de su biología y subjetividad. Él puede entenderse como un «cuerpo bioconstruido»: aquel cuya biología ha sido intervenida por la ciencia y la tecnología, y que nos obliga a asignarle nuevos significados y valores morales para poder comprender esa fusión entre lo humano y no humano. Sin duda, el futuro va a hacer realidad la existencia de estos cuerpos bioconstruidos.

En noviembre de 2013, The New York Times publicó un artículo del físico japonés Michio Kaku en donde compartía una lista de diez experiencias de la vida cotidiana que serían transformadas por la tecnología en las siguientes décadas. Dicha lista era el resultado de más de 300 entrevistas a científicos de distintas partes del mundo (Kaku, 2013). Este grupo de científicos predecía, entre otras cosas, que, en un futuro cercano, las partes averiadas del cuerpo serán reemplazadas por órganos cultivados en los laboratorios, los padres podrán escoger los rasgos genéticos y estéticos de sus hijos por un costo de 100 USD, y el proceso de envejecimiento se hará más lento gracias a nano-robots que se pasearán por nuestros organismos detectando y desechando rastros de cáncer y enfermedades que puedan afectarnos (Kaku, 2O13).

$\mathrm{Si}$ «el futuro es ahora», podría decirse que vivimos en un tiempo en el que muchas de las cosas mencionadas en este artículo ya comienzan a hacerse realidad en laboratorios y hospitales alrededor del mundo. Actualmente, se fabrican y comercializan «medicamentos vivos», fabricados con células madre capaces de regenerar tejido de úlceras diabéticas en pocos días (Apligraf, 2018). Se intenta reutilizar corazones que sirvan para trasplantes (Texas Heart Institute, 2018) y se imprimen «orejas humanas optimizadas», construidas a partir de material biológico y elementos electrónicos 
que permiten escuchar ondas de radio (Sullivan, 2013). Entonces, ¿cómo no imaginar el futuro a partir de estos nuevos cuerpos bioconstruidos?

El presente artículo presenta los principales hallazgos de una investigación que intenta construir un puente entre la bioética, la antropología y los estudios de la ciencia y la tecnología, para indagar sobre las expectativas y las estrategias de domesticación que un grupo de jóvenes aplica para dos casos de la vida real, en los que el uso y comercialización de artefactos transformarán drásticamente el cuerpo y la subjetividad de un ciudadano colombiano para el año 2034. Para esto se diseñaron cinco espacios de participación ciudadana en los que se aplicaron dos técnicas prospectivas (talleres y grupos focales), en las ciudades de Cali y Bogotá durante 2014 .

Esta propuesta metodológica prospectiva y su énfasis en la realización de actividades grupales fueron diseñados bajo el supuesto de que en Colombia no existen espacios en los que los ciudadanos puedan informarse y debatir sobre el uso de estas nuevas tecnologías. Un segundo supuesto es que la forma en la que imaginamos el futuro depende del contexto social en el que vivimos en el presente. Por lo anterior, es importante señalar que las vivencias y temores de estos jóvenes con respecto a la violencia en contextos urbanos y la experiencia del conflicto armado en nuestro país permearon los futuros que los setenta y nueve (79) participantes de esta investigación imaginaron para los casos seleccionados. Es así como estos cuerpos bioconstruidos son víctimas y victimarios del conflicto armado colombiano, viven bajo el temor de ser secuestrados y sortean los problemas de corrupción del sistema de salud, entre otras situaciones.

\section{Metodología}

En el marco de esta investigación, se conformaron cinco (5) espacios de participación ciudadana que permitieron la aplicación de dos técnicas prospectivas: un taller y un grupo focal. Esto se diseñó con la intención de orientar el proceso por el cual estas personas hacían sus prospecciones, ya que, para pedirles que imaginaran el futuro de estos cuerpos bioconstruidos, se siguió un orden particular. La realización de talleres al inicio de cada espacio, por ejemplo, les permitió a los participantes leer los casos, desarrollar una guía, escribir las expectativas que estos les generaban, interactuar con los otros participantes y vencer su timidez para poder participar en el grupo focal. La investigadora partió aquí de otro supuesto: hablar sobre el futuro y la forma en la que se imagina, frente a una grabadora, no es algo sencillo, por lo que aplicó esta técnica para despertar la imaginación de los participantes. 
Seguido a esto, y tras encender la grabadora de voz, se aplicó la segunda técnica: el grupo focal. Gracias a la aplicación de un guion, la investigadora pudo seguir decantando las categorías de análisis que orientaban la prospección y encaminar la discusión. Más allá de tratarse de una actividad basada en un formato pregunta-respuesta, esta actividad le permitió a la investigadora moderar un diálogo entre participantes y de estos con los casos. Para comprender mejor el diseño y la intención de esta propuesta metodológica, se explicarán a continuación los elementos que la conforman.

\section{Los participantes}

El estudio fue desarrollado con jóvenes entre los 18 y 25 años de las ciudades de Cali y Bogotá que se encontraban cursando una carrera universitaria, con el fin de realizar un análisis comparativo de sus respuestas. Esto se debe a que la investigadora deseaba indagar si el acceso a educación superior y las diferencias entre vivir en la capital del país y una ciudad intermedia incidían en la forma en la que imaginaban el futuro de estos cuerpos bioconstruidos. Pero también fueron elegidos por pertenecer a una generación que ha sido partícipe de varios adelantos tecnológicos y que ha integrado el uso de diferentes artefactos tecnológicos en su cotidianidad. Nunca se tuvo la intención de pensar la categoría de joven como enfermo o paciente, madre o padre de familia, entre otros; si estos casos llegaban, se debía a que se trataba de una convocatoria abierta. Cabe resaltar que estos ejercicios pueden y deben realizarse con poblaciones con características y demandas particulares, como también abarcar otras generaciones.

La convocatoria para participar en los grupos focales prospectivos de la ciudad de Cali se realizó a través de la red social Facebook y la técnica de voz a voz, con profesores universitarios que extendieron la invitación a los estudiantes de sus cursos. En esta ciudad, los únicos que respondieron a esta convocatoria fueron estudiantes de universidad privada. Los estudiantes que participaron en los grupos focales de Bogotá fueron convocados a través del Instituto de Bioética de la Pontificia Universidad Javeriana. En todas las convocatorias se ofertaba un espacio de participación ciudadana que promovía la reflexión y debate sobre nuevas tecnologías médicas, acompañado de buena comida.

Con el fin de preservar la confidencialidad de los datos de todos los participantes, se realizó el proceso de la firma de consentimientos informados al inicio de cada actividad. Llamó la atención la aprehensión y el temor que los participantes sintieron cuando se enteraron de que debían firmar este formato, así que se les reiteró que 
dicho documento servía para cuidar y brindar garantías sobre la confidencialidad de sus datos personales, el buen uso de la información que iban a brindar durante las actividades, la opción de retirarse cuando lo creyeran conveniente, pedir explicación cuando no entendiesen algunos de los pasos de la actividad, entre otros. Seguido a esto, ellos escribieron en una escarapela el alias con el que querían ser identificados durante la actividad.

Tras la firma del consentimiento informado, los entrevistados diligenciaron una pequeña encuesta sociodemográfica que sirvió para tener un referente de la composición de la población participante en el estudio. En total, participaron setenta y nueve (79) personas en los grupos focales; veintitrés jóvenes (23) del sexo masculino y cincuenta y seis (56) del sexo femenino. La edad promedio de los entrevistados estuvo entre los diecisiete y los dieciocho años, no obstante, participaron estudiantes entre los 16 y los 27 años, pertenecientes en su mayoría a los estratos 3 y 6 . También se encontró que treinta y dos (32) de estos estaban afiliados al régimen contributivo de salud, y veintiocho (28) a salud prepagada. Tan solo uno (1) de ellos afirmó pertenecer al régimen subsidiado. Dieciocho (18) de estos no suministraron esta información, tal vez por descuido o por desconocimiento. La gran mayoría de los participantes provenían de las ciudades de Cali (22) y Bogotá (18); sin embargo, se encontró una población proveniente de diferentes ciudades y municipios aledaños a estas ciudades, y de otros países del continente.

De este modo, se contó con la participación de estudiantes de diferentes ciudades del suroccidente colombiano, como lo son Pasto (1), Popayán (1), Palmira (1), Buga (1); de todo el Eje cafetero: Armenia (1), Pereira (1) y Manizales (1); de ciudades del altiplano cundiboyacense como Ubaté (1), Choachí (1), Sogamoso (2) y Duitama (1); de la ciudad de Villavicencio (1) en los Llanos Orientales; de los Santanderes, específicamente de Bucaramanga (1) y Cúcuta (3); y, finalmente, se contó con la participación de personas de la Costa Atlántica, provenientes de las ciudades de Córdoba (1), Sincelejo (2), Valledupar (1) y Riohacha (2).

Igualmente, participaron estudiantes de países como la República Bolivariana de Venezuela, provenientes de las ciudades de Caracas (3) y Puerto Ordaz (1). También de la ciudad de Fortaleza Ceara (1) en la República Federativa de Brasil. Asimismo, se presentó el caso de un estudiante nacido en los Estados Unidos, en el municipio de Teaneck, estado de New Jersey (1). Once (11) de los participantes no brindaron esta información.

Cincuenta (50) de los participantes adelantaban sus estudios en el campo de la odontología. Sin embargo, los veintinueve (29) restantes cursaban entre primero y décimo semestre de las carreras de biología, antropología, economía, derecho, diseño industrial, filosofía, mercadeo internacional y publicidad, y sociología. Aunque por 
lo general las encuestas solo tienen preguntas cerradas, la investigadora introdujo una pregunta abierta de tipo prospectivo, en la que se les preguntaba a los participantes cuál era el trabajo de sus sueños, con el fin de introducirlos a la dinámica del ejercicio. Algunos reaccionaron con sonrisas al encontrar esta pregunta, otros entraron en conflicto y dijeron no saber qué querían hacer en el futuro. Sus respuestas señalan deseos por desempeñarse como investigadores, odontopediatras, crear su propia empresa, ser corredores de carros de Fórmula 1, ser cirujanos maxilofaciales o dirigir un museo. En otras palabras, brindaron pistas de cómo imaginaban su futuro.

\section{El diseño de espacios de participación ciudadana para la aplicación de técnicas grupales}

Hasta el momento, los estudios ELSA o ELSI ${ }^{1}$ han sido preponderantes en el campo de la bioética, pues permiten revisar los aspectos éticos, legales y sociales de nuevas tecnologías, así como la forma en la que opera la agencia de los diferentes actores en escenarios de innovación tecnocientífica (Brown, Rip, y Van Lente, 2003). Sin embargo, se ha hecho necesario incorporar a este tipo de enfoques otros métodos provenientes de las ciencias sociales que permitan captar cualitativamente y de manera más crítica la opinión del público no experto. Por lo tanto, un primer objetivo metodológico de esta investigación es crear puentes entre la bioética y otros campos, para así integrar técnicas experimentales prospectivas que no solo capten información, sino que permitan crear espacios de participación ciudadana.

De este modo, la sociología del futuro y los estudios sociales de la ciencia y la tecnología emergen como dos de estos campos que brindan herramientas para analizar y regular los impactos de las invenciones tecnológicas en la vida cotidiana de las personas (Selin, 2008; Felt, Fochler, y Winkler, 2010). Por un lado, la sociología del futuro puede definirse como un enfoque teórico que analiza la forma en que las expectativas del público sobre un avance científico tienden a influenciar el desarrollo, comercialización y difusión de este en el futuro (Selin, 2008). Por otro lado, los estudios sociales de la ciencia y la tecnología brindan herramientas teóricas y metodológicas que cuestionan y denuncian el impacto de la producción tecnológica en la población en general, junto a los dilemas bioéticos a resolver, al gestionar y promover espacios de investigación que fomentan la participación ciudadana en Estados Unidos y varios países europeos (Selin, 2008; Felt et al., 2010).

1. Implicaciones Éticas, Legales y Sociales (Ethical, Legal and Social Implications). 
Varios gobiernos alrededor del mundo se han beneficiado de estas investigaciones, gracias a que brindan luces para el desarrollo responsable de las tecnologías clínicas, de cara a la incertidumbre y a los dilemas bioéticos que conllevan. De esta manera, convocar a diferentes actores sociales a espacios de participación ciudadana en el contexto de una investigación permite el diseño e implementación de técnicas grupales de recolección de información, como son los grupos focales, juegos de mesa, seminarios, talleres, encuestas en línea, entre otros. Estas han sido algunas de las herramientas empleadas comúnmente para estimular la participación de pacientes, cuidadores, personal de salud y científico, y personas del común en dichos contextos (Felt et al., 2010). Esto les ha permitido a los científicos sociales, vinculados a los campos nombrados anteriormente, analizar los impactos bioéticos y las implicaciones sociales que se desprenden de fenómenos tecnocientíficos a futuro. Sobre estas premisas la investigadora diseñó estos espacios de participación ciudadana.

El diálogo entre las expectativas de los ciudadanos y la promoción de estos adelantos científicos ya ha comenzado a hacerse visible en el diseño e implementación de políticas públicas en varios países, permitiendo expandir las ofertas de los planes de salud. Por ejemplo, ahora las familias cuentan con la posibilidad de criogenizar el cordón umbilical de un neonato con futuros fines terapéuticos, la creación de bancos de tejidos humanos, los diagnósticos moleculares durante el embarazo, entre otros (Brown et al., 2003). No obstante, este tipo de diálogo entre la academia, el Estado y los ciudadanos sobre temas en salud, en Colombia, aún requiere de más atención y movilización.

Por lo anterior, la investigadora desea recalcar «la necesidad de que la bioética acoja del todo a la etnografía crítica, como un enfoque metodológico fundamental» (Sharp, 200o, p. 317). Sin duda, el diseño de investigaciones de corte etnográfico, cualitativo y prospectivo realizarán un aporte importantísimo al campo de la bioética en Colombia, al permitir incorporar las expectativas y vivencias de diferentes actores en la comprensión y resolución de dilemas éticos en el campo de la salud y en contextos de desarrollo tecnocientífico. Pero, además, invita a pensar el uso de las técnicas cualitativas más allá de su función de captar información, y más como herramientas para construir espacios de diálogo, reflexión y participación ciudadana, sobre cuestiones del cuerpo, procesos de salud y enfermedad, entre muchos otros.

\section{Referentes metodológicos y teóricos}

La sociología del futuro es un enfoque teórico y metodológico que permite analizar la forma en que las personas construyen distintas versiones del futuro a partir de 
las expectativas que les despierta un determinado avance científico. Varios autores señalan que estas expectativas no solo manifiestan la manera en que las personas imaginan y se proyectan a largo plazo, sino que también tienen el poder de influenciar el desarrollo, comercialización y la difusión de un determinado producto (Borup, Brown, Konrad, Van Lente, 2006; Selin, 2008). Por lo anterior, una persona puede hacer una prospección cuando permite que sus «expectativas»o «prospectos» expresen las representaciones que ella construye en tiempo real, sobre desarrollos tecnológicos en el futuro.

Las expectativas estimulan la memoria y la imaginación de las personas, produciendo prospectos retrospectivos (Retrospecting prospects) que constituyen una primera forma de registro sobre su versión del futuro, y hacen alusión al «recuerdo de 'futuros pasados' o la manera como el futuro solía ser representado» (Brown y Michael, 2003, p. 4). La segunda forma de registro o retrospecciones prospectivas (Prospecting retrospects) permite captar «la manera en la que los sujetos hacen uso de estos prospectos (expectativas) en tiempo real, para construir [distintas versiones del] futuro» (Brown y Michael, 2003, p. 4). Entender cómo funcionan las expectativas del grupo de jóvenes entrevistados permitió diseñar y analizar la información obtenida durante los talleres, ya que fue aquí donde se captó el primer registro de los prospectos frente a los casos.

El otro enfoque teórico que permitió el diseño de los grupos focales fue la propuesta de la filósofa Martijntje Smits (2006) sobre la «domesticación cultural de monstruos biotecnológicos». Esta autora parte de la premisa de que la gente del común no rechaza los eventos biotecnológicos (o tecnológicos) por miedo o ignorancia, sino porque estas situaciones trasgreden las categorías morales con las que cotidianamente se clasifican los eventos sociales y biológicos (Smits, 2006). Esta propuesta teórica rescata varios de los postulados de la antropóloga Mary Douglas (1973) para explicar cómo la ambigüedad que generan los adelantos tecnocientíficos puede ser analizada a partir de la categoría de «monstruo»: un fenómeno que encaja simultáneamente en dos categorías morales o culturales que son mutuamente excluyentes, o que no encaja en ninguna (Smits, 2006).

Smits (2006) señala que una categoría moral es sinónimo de una categoría cultural, ya que alude a la manera como una comunidad, partiendo de sus hábitos, normas, costumbres, prácticas y creencias, construye y designa palabras para nombrar y explicar el valor social y moral de las entidades humanas y no humanas que conviven con esta en un territorio o momento histórico particular. El proceso por el cual se da el juego de palabras que permite mezclar o construir dichas categorías que explican la naturaleza de un monstruo es de larga duración, ya que por lo general se trata de un fenómeno o de una entidad cuya naturaleza híbrida, una mezcla 
entre elementos humanos (orgánicos) y no humanos (tecnológicos), solo puede ser analizada y decantada por etapas o estilos. De este modo, la autora propone cuatro estilos de domesticación cultural de estos monstruos.

El primer estilo o «exorcismo» se da cuando los monstruos biotecnológicos son rechazados por una comunidad por no encajar en las categorías culturales existentes. No obstante, estas entidades pueden resurgir bajo otra forma, obligando a las personas a seguir con el proceso de domesticación. Por tal motivo, se puede dar el segundo estilo o «adaptación», que consiste en la creación de categorías culturales o morales que permitan darle un nombre a esta entidad o fenómeno ambiguo, describir su naturaleza y ubicarlo en el lenguaje cotidiano (Smits, 2006).

Una vez se crea una categoría y, poco a poco, se hace uso de esta, se da el tercer estilo de domesticación o «acogimiento», paso en el que las personas acogen la categoría cultural y se le atribuyen características místicas al monstruo, permitiendo inscribirlo como un santo o un milagro de la ciencia, acercándolo más a la experiencia humana o divina (Smits, 2006; Quiceno, 2016). Esto permite establecer normas y prácticas cotidianas que median la interacción entre estos monstruos y los seres humanos. Por último, se da la «asimilación», dando cuenta de que, aunque el monstruo no haya sido comprendido del todo, ya no es objeto de extrañamiento, instalándose así en los modos de vida de las personas por vía de expansión de sus sistemas de clasificación (Smits, 2006). Aquello que es nombrado, existe. Así sea de manera monstruosa.

Estos estilos de domesticación cultural o moral sirvieron para ayudar a estos jóvenes a proyectar y delimitar sus propios prospectos retrospectivos y las retrospecciones prospectivas a propósito de los casos propuestos, en términos de categorías morales, prácticas cotidianas y estilos de domesticación que facilitaron la realización de la prospección y el posterior análisis de la información.

\section{Los casos analizados}

Al momento de seleccionar los casos para la realización de los grupos focales se tuvieron en cuenta dos criterios: debían ser historias de la vida real y debían acompañarse de imágenes capaces de causar un impacto visual. Para esto se buscaron ejemplos que hicieran alusión al uso de tecnologías médicas que transformarán visual y subjetivamente el cuerpo humano. Se revisaron fuentes secundarias como diarios de divulgación científica, prensa y páginas oficiales de artefactos o productos biotecnológicos. Incluso, se retomaron trabajos de artistas plásticos dedicados al tema de la genética. 
Esta información se consignó en seis afiches que exhibían la imagen de cuerpos o partes de este, transformados por el uso de tecnologías médicas, biotecnologías o un artefacto robótico, acompañado de una breve descripción del caso (no mayor a doce líneas). Las descripciones presentadas fueron elaboradas por la investigadora con base en la información técnica y médica disponible en las fuentes consultadas, en un esfuerzo de traducción de estas a un lenguaje públicamente inteligible. Algunos de los casos trabajados contaban la historia de Ian Tibbets y su testimonio de cómo volvió a ver gracias a la «osteo-odonto-queratoprótesis» (BBC, 2013), el uso de medicamentos celulares como Apligraf (2018) para regenerar tejido de úlceras diabéticas o venosas en cuestión de horas, y el diseño e impresión de una oreja humana que le permite a una persona escuchar más que un ser humano promedio (Sullivan, 2013).

No obstante, en este artículo solo se presentarán los hallazgos de dos de los seis casos propuestos. El primer caso se presentó con el nombre de «Corazones que vuelven a latir», el cual hace referencia a una nueva técnica experimental desarrollada por el Texas Heart Institute, en la que se reutilizan corazones extraídos de personas fallecidas o de animales como el cerdo para hacer trasplantes (Maher, 2013). El procedimiento consiste en retirar todo rastro de células y material genético del órgano por medio de detergentes especiales, para luego revivir dicho corazón al «bombardear» su matriz extracelular con células madre adultas ${ }^{2}$ provenientes del receptor.

El segundo caso fue presentado a los participantes con el nombre de «El cíborg militante: el color y sus sonidos». Aquí, el protagonista es Neil Harbisson. Tal como se explicó previamente, él es un ciudadano cíborg porque su autonomía depende del uso de un artefacto tecnológico para distinguir los colores (Montandon, 2010). Harbisson, junto al ingeniero Adam Montandon, creó un dispositivo electrónico o eyeborg, capaz de convertir el color en sonido. Además, creó la Fundación Cíborg para alentar a más ciudadanos a modificar sus cuerpos a partir de prótesis robóticas.

Gracias al esfuerzo del arquitecto y diseñador David Díaz, y del publicista Manuel Muñoz se realizó el diseño de los afiches y la corrección de los textos. Su ayuda fue vital para lograr materializar esta propuesta de metodológica. La búsqueda de estos casos llevó a prestar atención a cómo las opiniones y la percepción pública podrían imprimirles nuevos significados sociales a estas corporalidades bioconstruidas. Significados sociales que van más allá de un hecho biológico y que se configuran, por ejemplo, a través de las creencias, prácticas, categorías morales y estrategias de domesticación.

2. Las células madre adultas son aquellas células totipotenciales que conservan aquel don de convertirse en lo que el cuerpo necesite una vez nace, y se encuentran en la médula espinal, ósea o, incluso, en el tejido adiposo. Cuando estas son manipuladas a través de nuevas tecnologías, pueden convertirse en medicamentos que cumplen con la función de regenerar y construir tejidos, entre otros. 


\section{La dinámica del taller}

La primera parte de los espacios de participación ciudadana contó con la realización de talleres prospectivos basados en la propuesta de Emma Frow y Jane Calvert (2013), quienes le pidieron a un grupo de expertos en biología sintética que reflexionaran sobre los efectos de sus invenciones o productos a largo plazo. Esto les permitió a ellas explorar cómo este grupo de científicos imaginan y construyen diferentes versiones del futuro al reflexionar sobre las implicaciones sociales y bioéticas de sus creaciones. Para esto, diseñaron una guía y escribieron en cartulinas frases sugestivas sobre los impactos de un producto obtenido por biología sintética.

La investigadora se basó en la dinámica de esta actividad para diseñar los talleres, pero difiere de esta por el uso de afiches y el diseño del instrumento que guio la actividad. Al inicio de cada taller, se les pidió a los participantes leer todos los casos. Seguido a esto, se les entregó la guía y se les pidió que la desarrollaran basándose en el ejemplo que más les hubiese llamado la atención, ya fuese en solitario o en compañía de otros participantes que también se hubiesen inclinado por el mismo. Dicha guía estaba conformada por dos pasos.

El primer paso consistió en darle un nombre o sobrenombre a la persona de la que se hablaba en el caso o que imaginaran a una persona que hiciese uso del producto o tecnología nombrado ahí. En otras palabras, se les pidió construir una categoría cultural o moral que les sirviera para familiarizarse con ese cuerpo bioconstruido y describiera su naturaleza. Durante el segundo paso del taller, se les pidió escribir en cartulinas de diferentes colores el mayor número de causas y consecuencias que pudieran imaginar para el evento seleccionado; como referente, se les pidió escribir al menos tres de cada una. La cartulina amarilla sirvió para escribir las causas y la azul para escribir las consecuencias. Así, las causas apuntaban a sus propias explicaciones sobre los «cómo» o los «por qué» del surgimiento de esta técnica o biotecnología clínica en particular; imaginar múltiples orígenes para el caso escogido. Las consecuencias hacían referencia a las expectativas, las implicaciones sociales y los dilemas bioéticos que podrían darse si dichas tecnologías y transformaciones corporales llegaran a implementarse para el año 2034 en Cali o Bogotá (dependiendo del sitio donde se llevara a cabo la actividad).

\section{La dinámica de los grupos focales}

Con el fin de integrar los referentes teóricos y metodológicos descritos en esta parte del artículo, la investigadora diseñó un guion para la aplicación de la segunda técnica que, en este caso, fue la de grupos focales. A partir de la forma en la que estos 
jóvenes proyectaban y decantaban sus expectativas basadas en el taller sobre las causas y consecuencias, la guía de preguntas de las entrevistas grupales cumplía la misión de concretar estos prospectos en términos de las prácticas y estrategias para domesticar culturalmente dichos cuerpos bioconstruidos.

Pero esta guía de preguntas no solo se agotó en la indagación de prospectos y estilos de domesticación. Se diseñaron preguntas abiertas que exploraban situaciones hipotéticas que los llevaran a reflexionar sobre temas como el significado que ellos le atribuyen al cuerpo; el de la mercantilización (Sharp, 200o), la propiedad y la privacidad del cuerpo (Everett, 2007); el problema que se deriva de patentar células o genes; entre otros. Los participantes asociaron estas situaciones hipotéticas a temores y prácticas culturales de su cotidianidad: la corrupción que vive el sistema de salud colombiano, la falta de ética del personal médico, la existencia de una red de tráfico de órganos y tejidos, el miedo a que bandas criminales se conviertan en cuerpos bioconstruidos para causar más daño, por ejemplo. Al final, se les pidió a los participantes brindar pautas sobre las actividades que ellos creen pueden llevar a movilizar la educación y participación de los colombianos frente a estos temas.

Vale la pena resaltar que la cercanía de estos jóvenes con la ciencia ficción y los videojuegos les permitió comprender el lenguaje y las situaciones presentadas por la investigadora. Lo anterior se define como «fenómeno de cultivación» (Nuffield Council on Bioethics, 2012), el cual alude a la configuración de las expectativas de las personas sobre una nueva tecnología a partir del género de la ciencia ficción. Este tipo de análisis ha demostrado cómo la exposición a escenarios ficticios puede condicionar las expectativas de los sujetos sobre estas tecnologías clínicas en la vida real:

Digamos que hay muchas películas y ahora la ciencia ficción habla de estos temas, porque yo pienso que los directores ven el futuro. Entonces digamos que Eliysium (2013), Los juegos del hambre (2012), [entre otras películas], te muestran que tienes que competir por derechos que supuestamente iniciaron siendo democráticos. $Y$ también, no sé, la posibilidad de crear, no sé si es viejo, pero digamos que la creación de bebés para [tratar a] los niños con leucemia, se ve en esa película de My sister's Keeper (2009). (Joaquín, GF3). ${ }^{3}$

Es importante aclarar que esta propuesta metodológica no está orientada a predecir el futuro y, mucho menos, a dejar de lado las incertidumbres que rodean los casos que los participantes analizaron (Frow y Calvert, 2013). Por el contrario, los

3. La nomenclatura utilizada corresponde a la cronología en la que fueron realizados los grupos focales. Los grupos focales GF1, GF2 y GF3 corresponden a los espacios realizados en la ciudad de Cali. Los grupos GF4 y GF5 fueron realizados en la ciudad de Bogotá. 
enfoques teóricos y metodológicos implementados en el diseño de estos espacios de participación ciudadana permitieron identificar «áreas de incertidumbre bioética» que podrían servir para crear respuestas prácticas o diseñar políticas públicas que permitirían mitigar los efectos negativos de los imprevistos propios de las tecnologías médicas que transformarán los cuerpos del mañana.

\section{Los hallazgos: corazones que vuelven a latir y el cíborg militante}

En un principio, la investigadora había estimado que la domesticación cultural de estos monstruos haría alusión a situaciones y características puntuales de las ciudades de Cali y Bogotá. No obstante, las respuestas fueron bastante generales y no hicieron alusión a estos lugares. Un factor que se puede resaltar aquí es que varios de los participantes señalaron que muchos de estos casos los habían discutido en algunas de sus clases de pregrado, pero fue su exposición a las redes sociales y a la información disponible en internet lo que les permitió entender los casos o que afirmaran haber seguido la noticia de varios de los ejemplos tratados durante la actividad.

La investigadora esperaba que los guiones elaborados para los grupos focales permitieran reconstruir el proceso de domesticación de cada uno de estos cuerpos bioconstruidos en el sentido smitsiano (Smits, 2006), siguiendo los estilos de domesticación de manera cronológica. No obstante, se encontró que las retrospecciones prospectivas (Brown y Michael, 2003) de estos jóvenes partían de la asimilación total de cada una de estas tecnologías y de los cuerpos que las encarnaban (Smits, 2006). De este modo, la asimilación de estos monstruos fue el punto de partida del que los participantes comenzaron a señalar las lógicas exorcizadoras o de acogimiento con las que hacían sentido de estas bioconstrucciones en 2034 (Smits, 2006). A continuación, se analizan algunos de los principales hallazgos correspondientes a los casos.

\section{Corazones que vuelven a latir}

El cuerpo es el instrumento que nos permite interactuar con el mundo que nos rodea (Detréz, 2002); pero, además, es una entidad polisémica porque se le atribuyen diversos significados dependiendo de las situaciones y las realidades sociales que habita (Le Breton, 2002). Los cuerpos adquieren un valor simbólico o significados que van más allá de lo biológico; esto tiende a movilizar identidades, construir y ejecutar técnicas corporales para habitar el mundo e interactuar con otros seres humanos 
(Mauss, 1979). Es justo esta interacción con y a través del cuerpo lo que construye ideas de persona: «la persona es entendida como un compuesto de relaciones, un proceso marcado de la transformación y las conexiones que le van dando forma [...] las relaciones no son las que conectan a las personas, sino las que crean y permiten su existencia» (Strathern (1991- 1992), como se citó en Quiceno, 2016, p. 92).

Imaginar estas interacciones y estos cuerpos fue lo que permitió que los jóvenes imaginaran dichos casos en situaciones y contextos familiares. Y son estos elementos de la vida cotidiana los que hicieron que un «corazón fantasma» se convirtiera en un cuerpo bioconstruido. En un principio, la domesticación cultural de este caso lo situaba en el estilo de asimilación (Smits, 2006), gracias a sus características milagrosas y a los beneficios que trae para las personas en espera de un trasplante. Durante el taller, los participantes decantaron dichas características en las categorías culturales determinadas para este cuerpo bioconstruido: «blanqueado de órganos» (GF3) y «vida compartida» (GF1); además de «corazón anónimo» (GF4). Estas categorías resumen las preocupaciones de los jóvenes en torno a la procedencia de los corazones que portarán los cuerpos bioconstruidos tratados con esta tecnología y hacen alusión a las creencias, prácticas e interacciones sociales que sitúan al corazón como el órgano que alberga emociones.

Esto es lo que terminó llevando el caso de la asimilación al exorcismo. ¿Por qué? Por un lado, las causas atribuidas por los sujetos entrevistados al desarrollo de esta tecnología hicieron alusión a la necesidad de acceder a ella por la falta de donantes $(\mathrm{GF} 1)$ y las altas tasas de rechazo de órganos tras un trasplante (GF3). Estos son elementos positivos que permitirían que dichos cuerpos bioconstruidos se hagan realidad. No obstante, el estilo de exorcismo emerge a través de las consecuencias imaginadas para estos cuerpos: «puede darse una sobrepoblación» (GF4) o que la «búsqueda de dinero (negocios sucios)» (GF4) lleven a las personas a efectuar acciones ilegales como la «profanación de tumbas» y la «[creación de] un criadero de personas que sirvan como futuros donantes (de corazones)» (GF3). Estos hallazgos durante el taller prospectivo sirvieron para identificar que el exorcismo de este caso se produjo en dos vías: a partir de la creencia de que existe un mercado negro de órganos y tejidos en Colombia, y el peso que tienen los valores o los significados simbólicos de un órgano como el corazón.

\section{Un mercado negro de partes del cuerpo}

Existen varios trabajos pioneros que se han dado a la tarea de denunciar los abusos de la industria biotecnológica desde finales del XX (Andrews y Nelkin, 1998; Sharp, 
2000; Everett, 2007), en los cuales se muestra cómo el robo o la venta de partes del cuerpo son acciones que datan de mediados del siglo XVIII, cuando los estudiantes de medicina empezaron a necesitar cuerpos para aprender. Lo preocupante es que muchas de estas prácticas siguen realizándose en el contexto de investigación biotecnológica (Mousourakis, 2010) y se han encontrado demandas de pacientes cuyas partes del cuerpo han sido vendidas y convertidas en patentes. ${ }^{4}$

En 2007, la World Health Organization reveló un estudio en el que señala que un quinto de los 70 ooo riñones trasplantados en 2004 provenía del mercado negro, debido a la escasez de órganos que se experimenta alrededor del mundo (Shimazono, 2007). El Parlamento Europeo (2015) realizó otro estudio en el que señala que, a finales del siglo XX, el tráfico y comercialización de órganos y tejidos se realizaba en las regiones de India y del sudeste asiático. En el siglo XXI esta práctica se ha extendido a países de América Latina, el norte de África y otras regiones donde la inestabilidad económica crea condiciones que posibilitan el tráfico.

En Colombia, los informes estatales ${ }^{5}$ señalan que existen alrededor de 2179 personas en lista de espera por un trasplante de órgano (Ministerio de Salud y Protección Social, 2015), y no existen registros de que este tipo de acciones ilegales se hayan efectuado en nuestro país. Sin embargo, una parte de estos jóvenes creen que el tráfico de órganos y tejidos es real en el país, y esto los lleva a imaginar un futuro en donde esta tecnología y estos cuerpos bioconstruidos serán exorcizados.

Vale la pena resaltar que durante la realización de estos grupos focales no se había aprobado la Ley 1805 de 2016, la cual presume que todo colombiano es donante, siempre y cuando no haya manifestado en vida lo contrario, e impide que algún familiar pueda oponerse a la decisión del paciente (Congreso de la República de Colombia, 2016). Es por esto que algunos de estos jóvenes imaginaron que en el futuro sería necesario dar incentivos monetarios a las personas para que donaran sus corazones:

Patricio: Muchos donarían si les pagaran

Carlina: $\mathrm{O}$ sea, que si a la familia le pagaran. $\left(\mathrm{GF}_{4}\right)$.

Lisímaco: Nadie lo va a hacer gratis

Tulio: ¡Eso sí! nadie lo va hacer gratis

Lisímaco: Primero yo, segundo yo

Tulio: Como está la sociedad y eso, el sistema hace que uno piense primero yo, segundo yo, y ya después lo que sobre para las demás personas. (GF5).

4. Ver información sobre el paciente John Moore y su demanda «Moore vs. Regents of the University of California».

5. Cada institución maneja sus propias cifras y no existe un informe global más reciente de las mismas. 
Lock y Nguyen (2010) han encontrado que en países del Medio Oriente es común brindar incentivos económicos para promover la donación de órganos y tejidos en vida. Estas remuneraciones ofrecen desde el pago de los estudios universitarios hasta el suministro de medicamentos que les brinden una buena calidad de vida a personas que, por ejemplo, han donado un riñón. Otro grupo de participantes creen que los incentivos no van a resolver el problema. Su mayor preocupación, para el futuro que llegaron a imaginar, es que la escasez de corazones dará pie a acciones violentas e ilegales para conseguir estos órganos y aplicar esta tecnología, lo cual, en últimas, agudizaría los problemas de corrupción que tienen lugar en el sistema de salud y favorecería el ambiente de violencia que se vive en el país:

Inés: Eso es un problema, por ejemplo, el de que si vos sos donante, te van a perseguir para matarte, porque sos un donante bueno o por el tráfico de órganos.

Agustina: En mi licencia de Estados Unidos dice gigante: «donante de órganos» y pues como pensando en eso, aquí sería totalmente diferente, sería un peligro. (GF1)

Joaquín: Lo que nosotros decíamos era que podría aumentarse la tasa de criminalidad, tendrían que matar a la gente para obtener donantes. O que hubiese un criadero de personas simplemente para esto.

Leonor: Como esa película, cómo es que se llama...

Elena: La isla. (GF3).

$\mathrm{Al}$ respecto, Lock y Nguyen (2010) mencionan que la creación de programas que incentivan la donación de órganos y tejidos permite que haya leyes más justas y personas más conscientes sobre los beneficios del tema, permitiendo que mitos y temores sobre la existencia de un mercado negro disminuyan notablemente. No obstante, este no es el caso de Colombia y los jóvenes creen que este tema raya en la ilegalidad. Esta idea se reforzó aún más cuando, por fenómeno de cultivación, estos jóvenes compararon el futuro imaginado con una película de ciencia ficción en donde se clonan seres humanos que luego son asesinados para que sus órganos y tejidos sirvan en trasplantes.

Al respecto, existen varios trabajos pioneros en antropología que han denunciado y reflexionan sobre la manera en la que el cuerpo no solo es fragmentado e instrumentalizado a través de las prácticas y el uso de tecnología médica, sino que, también, las partes de este se están convirtiendo en bienes con un alto valor monetario que pueden ser ofertados a un mejor postor (Sharp, 2000; Scheper-Hughes, 2002; Cohen, 2003). Dicho fenómeno se conoce como la mercantilización del cuerpo y señala que este se compone de partes que pueden ser separadas y comercialmente transferibles (Mousourakis, 2010). Esto ha llevado a entender al cuerpo como una 
entidad carente de sentido o significado y que puede reducirse a un bien, justamente a lo que se refieren los jóvenes cuando creen que los cuerpos pueden ser mercantilizados y vendidos a través del tráfico de órganos y tejidos.

En Colombia es difícil rastrear la existencia de un «mercado negro» o una «mafia» que controle la realización de trasplantes de órganos y tejidos. Si existe o no este mercado negro es una tarea que algún día debería ser etnografiada (si alguien se atreve), pero, por lo pronto, se detecta que es una de las creencias más arraigadas entre estos jóvenes y que hace que, en su versión del futuro, los cuerpos que poseen estos corazones sean exorcizados, debido a que se asocia esta práctica y tecnología a una mercantilización del cuerpo. Sin duda, es una creencia terrorífica que lleva a estas personas a desconfiar de las instituciones médicas y estatales, y la forma en la que se manipulará su cuerpo una vez mueran.

\section{De corazón anónimo a una vida compartida}

Un trasplante de órganos y tejidos obliga a un paciente y sus familiares a vivir un proceso que tiende a reordenar las categorías culturales por las que, ese nuevo órgano, cuerpo, será comprendido y acogido (Vynt, 2011). En una versión del futuro imaginada por estos jóvenes se ve este proceso de reordenamiento: en primer lugar, lo anormal de la apariencia fantasmagórica de los corazones que son manipulados por esta tecnología no parece ser domesticada o reducida a un beneficio terapéutico que se encarga de algo patológico, es decir, a un fallo fisiológico.

Para estas personas, lo «extraño» o lo que debe domesticarse en este caso es que la apariencia de este corazón da cuenta de una técnica que ha logrado quitarle su historia, tanto biológica como social a ese órgano, a través de un medio artificial y no uno natural. En palabras de Alicia (GF1): «a mí me llamo mucho la atención lo del corazón, por lo del detergente que quita como todo... y yo lo asimile como cuando uno coge algo y lo echa en límpido, y [luego] vuelve y lo tiñe». Pero un corazón no es una cosa o una prenda de vestir, es probablemente uno de los órganos que más carga simbólica tiene, ya que, a este, por ejemplo, se le asocian las emociones.

Este es un claro ejemplo de lo complejo que resulta comprender la manera en la que las personas interpretan las partes de su cuerpo, debido al carácter polisémico del mismo. Pero, además, es un punto que refuerzan las preocupaciones de estos jóvenes sobre la mercantilización del cuerpo en su versión del futuro, por el uso de esta tecnología. Es por esto que se hace necesario describir el tipo de creencias que salieron a relucir durante este ejercicio de domesticación, con el fin de comprender 
algunos de los significados que ellos otorgan a esta parte del cuerpo y a los cuerpos bioconstruidos que lo portarán.

Una de las creencias que más destacaron los participantes es que las partes del cuerpo poseen una «memoria orgánica» que puede llevar al receptor de un órgano o tejido a heredar los rasgos sociales de la persona que lo donó:

Domitila:Y también que muchas personas creen que la materia orgánica tiene memoria y eso. Como el episodio de Los Simpsons cuando Homero recibe el trasplante de pelo del ladrón, iy se vuelve malo! (GF2).

Eliza: Yo creo que a diferencia de los demás, el corazón puede tener una connotación más especial y pueda que esto lo haga más polémico; yo leí una vez que una señora que había recibido un trasplante de corazón decía tener recuerdos extraños sobre querer a personas que ella no conocía. Le llegaban recuerdos de la nada como por decir algo: «ay, yo quise tanto a fulanito», pero ella no los conocía. Entonces es como vivir con una mini identidad que no es tuya, como no tener mayor control sobre lo que es tuyo. (GF3).

Los órganos y tejidos, una vez se separan del cuerpo, son llamados «sujetos liminales», tal como lo explica Squier ((2004) como se citó en Lock y Nguyen, 2010): aquellas partes de un cuerpo que cuentan la historia de vida de un donante. Muchas veces no somos conscientes de las otras partes que componen nuestros cuerpos y que también hablan de nuestros hábitos, costumbres y demás. Por ejemplo, yo nunca había pensado en el significado que le doy a mis células u otras partes minúsculas de mi cuerpo, pero esta investigación me ha llevado a cuestionar la manera en que construyo y los otros construyen, el valor simbólico de estas partes. Me ha llevado a recordar que mi cuerpo se compone de las mismas.

Lock y Nguyen (2010) han encontrado que un gran número de pacientes trasplantados en Estados Unidos entran en un estado de ansiedad que obliga al personal de salud a darle cierta información sobre la procedencia de su nuevo órgano. Lo que más les preocupa saber a estos pacientes es el género del donante, el color de su piel y algunos hábitos alimenticios, ya que creen que algunos de estos rasgos se han transferido a sus cuerpos.

No obstante, varios de los jóvenes imaginaron que, en caso de llegar a ser pacientes trasplantados y convertirse en cuerpos bioconstruidos, se negarían rotundamente a conocer datos sobre la persona que les donó su corazón. Esto se debe al temor que les genera saber las condiciones en las que se extrajo el órgano y la forma como murió el donante. De nuevo, ellos creen que los corazones se van a obtener a partir del asesinato de personas: 
Elsa: Pues yo he leído casos en los que la gente siempre quiere saber quién le donó el corazón, cómo era su vida, yo pienso que sí

Alicia: Yo no

Inés: A mí no

Josefina: No sé, ya se murió, ya la esencia se fue

Inés: Sí, igual, ya es una persona muerta, ya es como raro ir e investigar

Josefina: No y para qué uno atormentarse Concepción: No y ¿si a esa persona la mataron? (GF1).

Matilde: Pensar en cómo murió y que vos digas en ese momento que el corazón [trasplantado] está bien, pero de pronto también [al que donó] lo pudieron haber envenenado o algo, y que la persona a la que le han implantado ese corazón después de un tiempo se muera, porque ese veneno aún estaba ahí. (GF2).

Llama la atención que el tipo de muerte que experimente el cuerpo del cual será extraído el corazón también incide en las categorías culturales y los significados simbólicos con los que será acogido ese órgano. La asociación que se hace del procedimiento o técnica con actos violentos, sin duda, termina exorcizando por completo la posibilidad de hacer uso de esta tecnología con el fin benévolo de restaurar la salud. Es aquí cuando la valoración ética del acto por el que se consigan estos corazones lo sitúa como un acto altruista que restaurará sus vidas o como un acto violento que trasgrede lo bueno y lo malo, lo humano y lo justo.

Frente a esto existe un vacío bibliográfico: las fuentes consultadas provienen de contextos donde la sensación de inseguridad y violencia permanente no siempre se hace presente en los relatos de las personas que participan en estos estudios prospectivos. Por lo tanto, un hallazgo significativo sobre cómo se trasgreden las categorías culturales y los valores morales que se asignan a estos cuerpos bioconstruidos tiene mucho que ver con la realidad de un país como Colombia.

\section{El cíborg militante: el color y sus sonidos}

«Lo que hoy muchos considerarían monstruoso se verá extremadamente mundano en el día de mañana» (Bess, 2008, p. 123). El hecho de que Neil Harbisson haya logrado estipular que su eyeborg es una parte de su cuerpo, y que su pasaporte lo ratifique, muestra cómo en el futuro estos cuerpos extraordinarios pasarán a ser como el de cualquiera de nosotros. Pero mientras esto sucede, en el presente, estos jóvenes señalan que por más que Harbisson pueda hacer algo impensable como escuchar los colores, sigue siendo un cuerpo enfermo o incompleto que carga una prótesis robótica para poder funcionar. 
Esto se hizo visible en las categorías construidas durante el taller prospectivo para este cuerpo bioconstruido: «El eyeborg» (GF1), «Neil Colorsound» (GF2), «Ojo Cyborg» (GF3), «Ojos de perro» (GF4), y «ADN canino» (GF5). Mientras las primeras categorías hacen alusión al artefacto que mejora el cuerpo de Harbisson, las otras son las construcciones metafóricas en las que la visión en blanco y negro de un perro sería similar a la forma en la que Neil Harbisson ve el mundo por su acromatopsia.

Algunas de las causas imaginadas durante el taller prospectivo para este cuerpo bioconstruido fueron: «lograr ayudar a las personas a tener las habilidades de un ser humano 'sano'» (GF1), o que «[la] drogadicción en estado de embarazo ocasionó la mutación» (GF5). Entre las consecuencias que se darán en el futuro por la existencia de este cuerpo, sobresale la siguiente:

El surgimiento de grupos fundamentalistas que defienden con violencia los ideales supuestamente naturales de ser humano y de ser cíborgs, generara una pugna biopolítica entre humanos y humanos perfeccionados como cíborgs, donde los cuerpos bioconstruidos ya no son minoría y ostentan el poder político y coercitivo. (GF3).

A través de la biopolítica, la vida se vuelve un objeto de control político que deriva a prácticas que direccionan la vida biológica y social de los seres humanos (Foucault, 2006). No obstante, los nuevos cuerpos que introduce la tecnociencia están produciendo nuevos significados y creencias sobre la naturaleza de la especie humana que parecieran, aún, no ser acogidos por las respuestas prácticas y estatales que regulan el uso que una persona hace de dichas tecnologías (Vynt, 2011). Esto se hace presente en el futuro imaginado por los jóvenes, donde los Estados no se molestaron por regular los límites de estas transformaciones corporales y, por ende, se producen este tipo de disputas.

Durante el grupo focal, este fue un caso que a simple vista fue asimilado por los jóvenes y varios demostraron tener conocimiento sobre la naturaleza del mismo. Ellos debatieron enfáticamente sobre cómo la vida cíborg ya hace parte de nuestra vida cotidiana y ya está siendo acogida por varios de los colombianos:

Policarpo: Cuando uno usa el Google Glass o lee sobre lo que se está haciendo para construir a Iron Man pronto, uno se da cuenta que ya vive en un mundo virtual a partir de programas como The Second Life. Domitila: Probablemente es por esto por lo que la mayoría de las personas en este momento, tienen un lado, entre comillas, cíborg que se refiere más que todo a la capacidad de relacionarse socialmente. Ese lado yo creo que ha evolucionado a un nivel cíborg, entre comillas, pero no es la misma palabra, pero es algo parecido. ¿Por qué? Por las redes sociales, por la forma en la que actualmente nos conectamos. (GF2). 
La antropóloga Eugene Thaker (2003) ha visto en el uploading la metáfora de una dinámica de transferencia de subjetividades a medios ubicados por fuera de los cuerpos. Ella describe que, en el futuro, una modificación en la capacidad neuronal de los cuerpos humanos permitirá que estos puedan transferir la información que alberga su mente a sistemas o espacios virtuales grandes e inmortales. En efecto, estos jóvenes perciben que ya se encuentran en este proceso cuando señalan que nuestra información más valiosa existe en algún lugar del internet, ya sea dentro de una red social o en forma de una nube imaginaria que sirve para almacenar todo tipo de información. Para estos jóvenes, esto constituye una extensión más del cuerpo o de la mente.

Llama la atención cómo Domitila (GF2) señala que todos ahora tenemos un «lado cíborg» por el uso que hacemos de nuestros dispositivos móviles. Es como si la asimilación (Smits, 2006) de esta tecnología nos permitiera a todos ser parte de esta comunidad, solo por el hecho de interactuar con espacios virtuales o de realidad virtual. Sharp (2000) señala que en esta dicotomía entre ser humano-máquina ha quedado recogida y, a la vez, resuelta la categoría cultural de cíborg que, entretanto, sigue difundiéndose a través de los medios y el cine.

Este, por ejemplo, es un caso exitoso del estilo de adaptación y acogimiento de una categoría cultural (Smits, 2006), ya que es una categoría que ha venido siendo domesticada a lo largo del siglo XX y los seres humanos ya reconocen la naturaleza de estos cuerpos. Sin embargo, y tal como lo señala Domitila, lo que ella describe no es una experiencia cíborg. Es algo que probablemente estamos adaptando (Smits, 2006) y aún no ha sido bautizado con una categoría en particular.

El cíborg que constituye Neil Harbisson no es del todo un cuerpo artificial, pues las nuevas materialidades que lo constituyen no son percibidas como una exterioridad, ni un cuerpo artefactual, ya que las partes no se comportan como medios perceptivos o funcionales, sino que son recursos de autorreferencia y sociabilidad que le permiten corregir una mutación genética (Sharp, 2000; Thaker, 2003). Este hombre-eyeborg, más bien, puede ser entendido como una prótesis sociotécnica (Haraway, 1990), un cuerpo bioconstruido:

Pues es algo que se ha ido construyendo y las personas son cada vez más propensas a pensar que es completamente aceptable tener algo que te mejora las capacidades. Sin embargo, la cualidad cultural que pueden tener estos son múltiples, e igual todos sabemos que ese tipo de realidades son completamente diferentes para cada entorno, entonces uno lo ve como el inicio de una nueva era, como de ir en contra de todo lo natural. (Modesto, GF2). 
La creencia en que los cíborgs irán en contra de todo lo natural y ocasionarán una deshumanización de lo corporal fue uno de los factores que incidieron en que estos jóvenes exorcizaran este cuerpo bioconstruido. El historiador Bess (2008) advierte que estas tecnologías cíborgs son para optimizar, ya que mientras los científicos aprenden a reparar cuerpos enfermos -como el de Harbisson- a través de estas, también aprenden a desarrollar artefactos que elevaran las capacidades del cuerpo a niveles no humanos:

Es que tiene sus pros y sus contras. Lo bueno es que le estarías dando las capacidades a una persona que no las tenía, de mejorar su calidad de vida. Pero entonces estarías haciendo tú a la persona y eso no es la vida. La vida [consiste en] que tú naciste así, Dios te creo así por algún motivo, para luchar y saber tu camino en la vida. (Julia, GF4).

Aunque cuerpos bioconstruidos, como el de Harbisson, advierten que este tipo de humanos híbridos o experiencias cibernéticas van a ser cada vez más comunes, estos jóvenes imaginan un futuro en donde los cuerpos cíborgs serán exorcizados (Smits, 2006) porque incitarán a personas sanas a optimizar sus cuerpos. Es aquí cuando ellos explican que a medida que las personas se involucren en la iniciativa cíborg de este personaje, se entraría a instrumentalizar la vida y se daría un proceso de deshumanización.

De entrada, estas tecnologías tienen el gran poder de transformar la esencia biológica de la especie humana, lo que nos impone la obligación de visibilizar las implicaciones bioéticas que traen consigo, los posibles usos futuros de estos procesos de investigación y producción. En la relación que hacen los jóvenes entre cíborgs y experiencias virtuales por fuera del cuerpo, se anuncian corporalidades emergentes y complejas en las que se amalgaman tecnologías robóticas, prostéticas e informáticas (Sharp, 200o). En este sentido, el cíborg denomina un modo de existencia corporal no limitada a los sentidos o dotaciones naturales, y menos al producto de un acoplamiento de partes orientado a la mera restitución de funciones corporales perdidas. Es un cuerpo bioconstruido en pleno proceso de domesticación cultural (Smits, 2006).

\section{Reflexiones finales}

La sistematización y el análisis de los resultados obtenidos tras este ejercicio prospectivo permitieron identificar varios elementos que sobresalen en las retrospecciones prospectivas (Borup et al., 2006) de estos jóvenes y en la domesticación cultural que hicieron de los casos. Llama la atención la manera en que los participantes resaltan 
elementos de su vida cotidiana y que aluden a la violencia rural y urbana de nuestro país; ejemplos como el secuestro y la corrupción del sistema de salud señalan cómo se dará la mercantilización del cuerpo y la creación de mercados negros en el futuro, en pro de una tecnología que promete mejorar la calidad de vida de pacientes en espera de ser trasplantados. Pero, por otro lado, se hacen visibles las preocupaciones con respecto al tipo de segregaciones sociales y disputas biopolíticas que traerá el uso y acceso a tecnologías robóticas. Este tipo de relaciones e interacciones hablan de cómo, al introducir otros significados para entender el cuerpo, también se puede llegar a transformar la idea de persona o sujeto (Strathern (1991-1992), como se citó en Quiceno, 2016).

Las versiones del futuro imaginadas por estos jóvenes señalan que es probable que haya cuerpos menos enfermos y más optimizados, tal como lo prometen este tipo de tecnologías médicas. No obstante, las situaciones que se viven en el presente en Colombia terminan determinando que el acceso a estas mejoras tecnológicas se dará por la capacidad económica de las personas y, en consecuencia, se producirá una segregación social ocasionada por el miedo a la apariencia de estos cuerpos bioconstruidos o porque habrá más personas enfermas por el alto costo de estos productos.

El advenimiento de seres humanos superiores, a causa de estas desigualdades socioeconómicas, incidirá en la manera en que nos relacionamos entre nosotros en el futuro. El proceso de domesticación cultural de estas tecnologías (Smits, 2006) en un país como el nuestro dependerá de las creencias, las prácticas que introducirá el uso de artefactos y tecnología médica, y de las categorías culturales y morales con las que se entenderán y juzgarán los cuerpos bioconstruidos. Pero es muy probable que el exorcismo inminente imaginado por estos jóvenes se retroalimente de la manera en la que pensamos y vivimos en nuestros cuerpos en el presente. Es por esto por lo que ejercicios cualitativos y prospectivos como este señalan por qué, a veces, las promesas del futuro tecnocientífico no son siempre bien recibidas por el público no experto.

Paralelo a esto, se encontraron varios temas transversales que no pudieron ser tratados en este artículo y que hacen alusión a los dilemas bioéticos que estos jóvenes debatieron y que guardan relación con la creación de patentes y las denuncias que ellos mismos hicieron sobre el robo de partes de cuerpos post mortem y del que fueron víctimas familiares o personas cercanas a ellos. Igualmente, se trató el tema de la autonomía de los embriones y el derecho a nacer con una biología que no ha sido diseñada por terceros e, incluso, temas como la fea apariencia estética que produce una tecnología prometedora como la «querato-odonto-prótesis».

Este tipo de respuestas tienen una riqueza cualitativa que destaca cómo la mirada no experta de los problemas sociales, políticos y éticos que trae consigo el uso y la producción o aplicación de una biotecnología o tecnología biomédica en un 
país como Colombia, puede y debe ser reconocida por los investigadores en toda su amplitud y complejidad, sobre todo si este tipo de trabajos defienden la pertinencia de modelos participativos para la producción regulatoria en este ámbito. Estas advertencias sobre los beneficios y los riesgos que trae consigo el desarrollo de tecnologías médicas ponen en crisis las distinciones o las taxonomías con las que los seres humanos clasifican los eventos a su alrededor. En Colombia y en América Latina se necesitan más trabajos que permitan indagar por estas expectativas a través del diseño de espacios de participación ciudadana.

Finalmente, la categoría de «cuerpos bioconstruidos» tiene un uso metafórico que exalta lo corporal como el resultado de un proceso biológico, pero también de deliberación social. Por un lado, un cuerpo bioconstruido es una entidad cuya perfecta imperfección puede ser moldeada y transformada por el uso de tecnologías médicas. Pero, por otro, hace alusión al significado que adquiere un cuerpo a través de su interacción con el mundo, con los otros, cuando ya ha sido transformado $u$ optimizado a partir de estas ayudas tecnológicas. De este modo, se invita al lector a reflexionar sobre estos cuerpos del mañana como unas construcciones sociales, culturales, políticas e históricas que serán domesticadas culturalmente como entidades monstruosas.

\section{Referencias bibliográficas}

ANDREWS, L., Y DOROTHY, N. (1998). Whose body is it anyway? Disputes over body tissue in a biotechnology age. The Lancet, 351, 53-57.

APLIGRAF. (2018). What is Apligraf? Recuperado de http://www.apligraf.com/patient/what_is_apligraf/how_is_apligraf_applied.html

BESS, M. (2008). Icarus 2.0: A historian's perspective on human biological enhancement. Technology and culture, 49(1), 114-126.

BORUP, M., BROWN, N., KONRAD, K., Y VAN LENTE, H. (2006). The Sociology of Expectations in Science and Technology. Technology Analysis \& Strategic Management, 18(3-4), 285-298.

BROWN, N., Y MICHAEL, M. (2003). A sociology of expectations: retrospecting prospects and prospecting retrospects. Technology Analysis o Strategic Management, 15(1), 3-18.

BROWN, N., RIP, A., Y VAN LENTE, H. (2003). Expectations in $\sigma$ about science and technology. Recuperado de https://www.researchgate.net/publication/46671758_Expectations_in_About_ Science_and_Technology 
BBC NEWS. (2013). The day I've got my sight back. Recuperado de http://www.bbc.co.uk/programmes/galleries/poijoh7k

COHEN, L. (2003). Where it hurts: Indian Material for an Ethics of Organ Transplantation. Zygon. Journal of Science and Religion, 38(3), 136-165.

CONGRESO DE LA REPÚBLICA DE COLOMBIA (2016). Ley 1805 de 2016: Por medio de la cual se modifican la Ley 73 de 1988 y la Ley 919 de 2004 en materia de donación de componentes anatómicos y se dictan otras disposiciones. Recuperado de http://es.presidencia.gov.co/normativa/ normativa/LEY\%201805\%20DEL\%2004\%20DE\%20AGOSTO\%2oDE\%2O2016.pdf

DETRÉZ, C. (2002). El cuerpo-instrumento. En La construcción social del cuerpo (pp. 37-45). París: Points.

DOUGLAS, M. (1973). Las abominaciones del Levítico. En Pureza y peligro. Un análisis de los conceptos de contaminación y tabú (pp. 63-81). Madrid: Siglo Veintiuno Editores.

EVERETT, M. (2007). The 'I' in the gene: Divided property, fragmented personhood and the making of a genetic privacy law. American Ethnologist, 34(2), 375-386.

FELT, U., FOCHLER, M., Y WINKLER, P. (2010). Coming to terms with biomedical technologies in different techno political cultures: a comparative analysis of focus groups on organ transplantation and genetic testing in Austria, France, and the Netherlands. Science, technology o human values, $35(4), 525-553$.

FOUCAUlT, M. (2006). Clase del 11 de enero de 1978. En Seguridad, Territorio, Población (pp. 15-44). Buenos Aires: Fondo de Cultura Económica.

FROW, E., Y CALVERT, J. (2013). Opening up the future(s) of synthetic biology. Futures, 48, 32-43.

HARAWAY, D. (1990). A cyborg manifesto: Science, Technology, and Socialist-Feminism in the Late Twentieth Century. En Simians, Cyborgs and Women. The reinvention of nature (pp. 149182). New York: Routledge.

KAKU, M. (2013).A scientist predicts the future. Recuperadodehttp://www.nytimes.com/2013/11/28/ opinion/kaku-a-scientist-predicts-thefuture.html?pagewanted=all

LE BRETON, D. (2002). Antropología del cuerpo y modernidad. Buenos Aires: Ediciones Nueva Visión.

LOCK, M., Y NGUYEN, V-K. (2010). The social life of organs. En An anthropology of Biomedicine (pp. 205-228). Oxford: Wiley-Blackwell.

MAHER, B. (2013). Tissue Engineering: how to build a heart. Nature: International Weekly Journal of Science. Recuperado de http://www.nature.com/news/tissue-engineering-how-to-build-aheart-1.13327 
MAUSS, M. (1979). Técnicas y movimientos corporales. En Sociología y Antropología (pp. 337-356). Madrid: Tecnos.

MINISTERIO DE SALUD Y PROTECCIÓN SOCIAL. (2015). Datos Globales de Donación y Trasplantes, 2014. Recuperado de https://www.minsalud.gov.co/sites/rid/Lists/BibliotecaDigital/ RIDE/VS/MET/Da tos-Globales-Donacion-Trasplantes.pdf

MONTANDON, A. (2010). Colourblind Eyeborg Colours to Sound. Recuperado de http://www. adammontandon.com/neil-harbisson-thecyborg/

MOUSOURAKIS, G. (2010). Body commodification and the human organ transfer in the biotechnological age: philosophical and ethico legal perspectives. Housei Riron, 43(1), 45-65.

NUFFIELD COUNCIL ON BIOETHICS. (2012). Biotechnology promises and expectations. En Emerging biotechnologies: technology, choice and the public good (pp. 22-38). London: Nuffield Council on Bioethics.

QUICENO, N. (2016). Cuerpos: fuerzas divinas y humanas. En Vivir sabroso. Luchasy movimientos Afroatrateños, en Bojayá, Chocó, Colombia (pp. 91-133). Bogotá: Universidad del Rosario.

SELIN, C. (2008). The sociology of the future: tracing stories of technology and time. Sociology Compass, 6(2), 1878-1895.

SCHEPER-HUGHES, N. (2002). Bodies for sale-whole or in parts. En N. Scheper-Hughes y L. Wacquant (eds.), Commodifying bodies (pp. 1-8). Londres: Sage Publications Ltd.

SHARP, L. (2000). The commodification of the body and its parts. Annual Review of Anthropology, $29,287-328$.

SHIMAZONO, Y (2007). The state of the international organ trade: a provisional picture based on integration of available information. Bulletin of World Health Organization. Vol. 85, No. 12. Visitado el 8 de julio de 2014. Disponible en: http://www.who.int/bulletin/volumes/85/12/o6-03937o/en/

SMITS, M. (2006). Taming monsters: the cultural domestication of new technology. Technology in Society, 28, 489-504.

SULLIVAN, J. (2013). Printable 'bionic' ear melds electronics and biology. Recuperado de http://www. princeton.edu/main/news/archive/S36/80/19M40/index.xml?section=t opstories

TEXAS HEART INSTITUTE. (2018). Regenerative Medicine Research. Recuperado de http://www. texasheart.org/Research/RegenerativeMedicine/index.cfm

THAKER, E. (2003). Data Made flesh: Biotechnology and the discourse of the posthuman. Cultural Critique, 53, 72-97.

VYNT, S. (2011). Introduction: Science fiction and biopolitics. Science fiction and televisión, 4(2), 161-172. 